\title{
ERP - Change Agent or a Legacy System in Disguise: A Chinese Case
}

\author{
Nasrin Rahmati ${ }^{1}$ and Gouyi Cao ${ }^{1}$ \\ 1 Monash University, Wellington Road, Clayton 3800, Australia \\ WWW home page: http://Www.infotech.monash.edu.au
}

\begin{abstract}
The paper is a report on a case study of a state-owned Chinese company. The study selected one simple business process and compared the process before and after the Enterprise Resource Planning system implementation. ERP systems promise to integrate business processes across an organization and in most cases are considered as an ideal Business Process Reengineering tool. The present study shows the impact of organizational culture on the use of ERP in an organization.
\end{abstract}

\section{Introduction}

Enterprise resource planning (ERP) systems are defined as "configurable information systems packages that integrate information and information-based processes within and across functional areas in an organization" [1, p. 22]. The major goal of ERP systems is to integrate and streamline business processes and their associated information and work flows [2]. Although these systems can deliver significant rewards such as improved customer service, better production scheduling, and reduced manufacturing costs, the risks related to their adoption are equally great [3]. ERP systems are Software packages which are developed on the basis of best practices promising integration across the organization. Integration, being packaged software and using best practice and the associated assumptions are suggested to be the main features of ERP systems $[4,5,6,7$, and 8].

Davenport, Hammer and Champy [3 \& 9] introduced the terminology "business process innovation" or "business process reengineering" to represent the radical change in the way "in which organizations work" compared with the incremental change of business processes in total quality management (TQM), which is the most accepted management philosophy in Japan. Gunasekaran and

Please use the following format when citing this chapter:

Rahmati, N., Cao, G., 2006, in International Federation for Information

Processing, Volume 205, Rescarch and Practical Issues of Enterprise Information Systems, eds. Tjoa, A.M., Xu, L., Chaudhry, S., (Boston:Springer), pp.241-246. 
Nath [10] identified three elements in BPR: organizational restructuring, exploiting information technology, and changing the participants' behaviors.

In theory, BPR can occur without IT; however a range of information technologies can be enablers of the reengineering business process [11 - 12]. IT and BPR "have a symbiotic relationship: without reengineering, information technology delivers little payoff; without information technology, little reengineering can be done" $[9$, p. 5]. As well as being applied to BPR at different levels and in different areas, IT can be a constraint on BPR, mainly because the legacy systems and architecture serve local function and result in an "information Island". In addition, the process thinking and the enabling potential of IT are necessary but not sufficient in BPR. "To realign operations, administration, management or inter-firm relationships with 'process' requires a fundamental shift in the way the whole business or organisation thinks and works" [12 p.27]. It has been widely recognized that human, rather than technical barriers present the major challenges in BPR [13 - 14]. Evans [13] claims that re-engineering is not the technical, IT-driven exercise many consider it to be; rather it should incorporate three key elements: a proper strategy, the use of enabling IT and the training of staff to understand the reengineering process. People are assumed to be able to adapt quickly to new ways of doing business in most BPR cases regardless of the changes required in their behaviour or work practices [14].

Cultural differences may significantly influence transferability and success when BPR is introduced in China, although most management ideas can be commonly adopted. This cultural difference contributes to a high failure rate of ERP implementation [15]. ERP systems function, as suggested by some authors such as Brehm et al. [16], on the basis of some assumptions regarding the business processes and the market in which the organization operates. Cultural "fit" with ERP systems might be a problem in Asia, because the reference processes model underlying most ERP systems is influenced by European or U.S. industry/business practices, which are different from those of Asian countries [17]. As organizations are encouraged to reengineer their business processes to match "best practice" in packages, there can be significant problems associated with the reengineering of local practices and processes [18]. There are national culture and organizational culture to be considered. Hofstede [19] proposed four dimensions of national culture. "Society is seen as a hierarchical pyramid of roles which entail fairly well established norms governing how people should act and behave in relationship to people in other roles. Social hierarchy and relations of subordination and superiority are considered natural and proper" $[8, p, 16]$.

The present study examines one case of ERP adoption in a State Owned Enterprise (SOE). The BPR through ERP adoption here refers to whether adopters reengineer their business processes to fit the software, or whether they customize the package to fit their business processes, or do both. The aim is to provide a rich picture of the change in business processes in case organizations, not to quantify the components of the studied phenomenon. The overall stance of research philosophy is the radical humanist approach proposed by Burrell and Morgan [20]. 


\section{The Case Company - MachineCo.}

MachineCo has almost 100 years history, changing from a simple workshop to a modern enterprise specialized in manufacturing specialized machines. Although MachineCo has made significant achievements since Chinese government carried out reform policy from 1978, it possesses traditional SoEs' characteristics. There are two points to be considered in MachineCo. First employees consider themselves are working for and being paid by the government. The second point to be considered here is that due to government policy, the company at present enjoys a low competition in the market. There has never been any serious competition and the profit has increased steadily in recent years. The industrial sector (machinery) the company engaged in is a very traditional sector in China. The demand increases steadily by a small rate without radical fluctuations. It seems that the government has decided to allow other companies to enter this market in near future. All MachineCo's customers are also traditional SoEs.

\subsection{Adoption of ERP Systems}

Through tender and case investigations of other corporations, 'Forth Shift ERP' system was employed. This system specializes in medium and small manufacturing enterprises and has gained good reputation in recent years in China. The adopted modules are production, storage management, purchasing, planning and order processing units. An ordinary department: information centre department is charge of the implementation of the system. ERP adoption process started in 2002 and the implementation went into its final phase by mid 2004. The case analyzed in this study was the purchasing process at MachineCo.

\subsection{Purchasing Process at Machine Co after ERP implementation}

The analysis focuses on Steps 1 to 6 of the company's purchasing process which become easier after the adoption of the ERP system because information about the required material for orders, current stocked materials and detailed data on suppliers are integrated. In Step 1, the market plan is generated by the planning module of the ERP system according to the currently received orders and product stock levels. This procedure is a complex process based on scientific calculation and prediction. Every product consists of a corresponding BOM, which provides detailed data about its consisting parts and prices. However, because it is difficult to accurately predict market demand, in Step 2 the plan produced by the ERP system is modified by users on the basis of their experience in the business environment. In most cases, the inaccurate prediction of market demand requires a manual change in the plan. In China, especially for SoEs, the decision-making process is highly influenced by irrational factors such as politics and "guanxi". MachineCo usually relies on the personal experience of employees and informal 
information to predict prospective orders. For example, if some signs indicate that the prices of raw material such as steel will increase in coming months, which could in turn cause an increase in the price of the parts, MachineCo increases its purchasing level. When staff in the purchasing department place orders generated by the ERP system in Step 5, they have to take non-technical factors into consideration to change the quantities ordered from different suppliers to some extent. However, if the supplier has a good personal relationship with MachineCo, the managers change the purchasing process to guarantee the desired order share for the supplier. This phenomenon is common in the Chinese business environment, especially in SoEs.

\section{Discussion}

Inadequate functions of the software package in quality inspection and the coding system of parts have been the major cause of delay in the implementation process. The problem has been solved with the help of the vendor by customizing relevant modules. The ERP system was implemented with the help of a consultancy company and was completed within the budget, but exceeded the planned time by one and half years. So it can be concluded that the ERP software can meet the requirements of BPR in functionality and flexibility. In addition to technical factors, the study examined the impact of environmental and organizational factors. Three "misfits" between environmental, organizational factors and ERP adoption and BPR implementation are:

- "misfit" Between Organizational, Environmental Factors and ERP Adoption

- "misfit" between Organizational, Environmental Factors \& BPR

- "misfit" Between ERP Adoption and BPR Implementation

Since the old business processes with the constraints of SoEs, were thought to be basically reasonable, the new business processes followed the old ones accordingly. MachineCo did not change its fundamental way of doing business. The only difference between the purchasing process before and after ERP implementation seems to be the elimination of some information exchange activities with the help of ERP system. The current improvement achieved through the reengineering business processes is marginal and limited. One reason is that since ERP implementation, many processes are still undergoing optimization. The other is that MachineCo did not undertake the essential changes required by BPR, such as organizational restructuring and assessment systems redesign. The important part of any process in the case organization is the negotiations and special social relations with the management, employees, customers and the local government and this cannot be embedded into the present software package. As a result it seems that the users have found different methods to incorporate the system into their work process to simplify the access to the data. The major factor in this case has been enjoying a monopoly in the market which is changing at 
present. With the competition there will be a need for more efficient process and it will have a major impact on the environmental and organizational factors.

\section{References}

1. K. Kumar and J. Van Hillegersberg, ERP Experiences and Evolution, Association for Computing Machinery 43(4), (2000).

2. M. Al-Mashari, Enterprise Resource Planning (ERP) Systems: A Research Agenda, Industrial Management + Data Systems 103(1/2), (2003).

3. T. H. Davenport, Process Innovation: Reengineering Work Through Information Technology, (Harvard Business Press, Boston, MA, 1993).

4. H. Klaus, M. Rosemann, and G. Gable, What is ERP? Information Systems Frontiers 2(2), 141-162 (2000).

5. S. Shang and P. B. Seddon, Assessing and Managing the Benefits of Enterprise Systems: The Business Manager's Perspective, Information Systems Journal 12(4), 263-353 (2002).

6. C. Soh, S. S. Kien, and J. Tay-Yap, Cultural Fits and Misfits: Is ERP a Universal Solution? Communications of the $A C M, \mathbf{4 3}(4),(2000)$.

7. T. H. Willis, and A. H. Willis-Brown, Extending the Value of ERP, Industrial Management + Data Systems, 102(1/2), (2002).

8. F. Xing, The Chinese Cultural System: Implications For Cross-Cultural Management Advanced Management Journal, 60(1), (1995).

9. M. Hammer, and J. Champy, Reengineering the Corporation: A Manifesto for Business Revolution, (Nicholas Brealy, London 2001).

10. A. Gunasekaran, and B. Nath, The Role of Information Technology in Business Process Reengineering, International Journal of Production Economics, 50(2-3), 91-104 (1997).

11. T. Curran, and G. Keller, SAP R/3 Business Blueprint, (Prentice-Hall, New Jersey, 1998).

12. M. Earl and B. Khan, How new is Business Process Redesign? European Management Journal 12(1), 20-30 (1994).

13. R. Evans, The Human Side of Business Process Re-Engineering, Management Development Review 7(6), 10-12(1994).

14. O. Marjanovic, Supporting the "Soft" Side of Business Process Reengineering, Business Process Management Journal 6(1), (2000).

15. J. L. Whitten, L. D. Bentley, and K. C. Dittman, Systems Analysis and Design Methods, (McGraw-Hill, Boston, Mass 2004).

16. L. Brehm, A. Heinzl, and M. L. Markus, Tailoring ERP Systems: A Spectrum of Choices and their Implications in Proceedings of the 34th Hawaii International Conference on System Sciences Conference, Hawaii (2001).

17. J. Swan, S. Newell, and M. Robertson, The Illusion of 'Best Practice' In Information Systems for Operations Management, European Journal of Information Systems 8(4), 284293 (1999).

18. R. Davison, Cultural Complications of ERP, Communications of the ACM, 45(7), 109111 (2002).

19. G. Hofstede, Culture's Consequences: Comparing Values, Behaviors, Institutions and Organizations Across Nation, (Sage Thousand Oaks, 2001). 
20. G. Burrell and G. Morgan, Sociological Paradigms and Organisational Analysis: Elements of the Sociology of Corporate Life, (Aldershot, Hants, Arena, 1994). 